\title{
Radiotherapy Dose Escalation with Concurrent Chemotherapy Improves Outcome in Locally Advanced Cervix Carcinoma
}

\author{
Hegazy MW ${ }^{1,2^{*}}$, Mahmood $\mathbf{R}^{1}$, Albadawi ${ }^{3}$, H Husaini ${ }^{4}$ and Moftah BA ${ }^{5}$ \\ ${ }^{1}$ Department of Radiation Oncology, King Faisal Specialist Hospital and Research Center, Riyadh, Saudi Arabia \\ ${ }^{2}$ Department of Clinical Oncology and Nuclear Medicine, Faculty of Medicine, Zagazig University, Egypt \\ ${ }^{3}$ Department of Gynaecologic Oncology, King Faisal Specialist Hospital and Research Center, Riyadh, Saudi Arabia \\ ${ }^{4}$ Department of Medical Oncology, King Faisal Specialist Hospital and Research Center, Riyadh, Saudi Arabia \\ ${ }^{5}$ Department of Biomedical Physics, King Faisal Specialist Hospital and Research C entre, Riyadh, Saudi Arabia
}

*Corresponding author: Hegazy MW, Department of Radiation Oncology, King Faisal Specialist Hospital \& Research Center, Riyadh, Saudi Arabia; Tel: +966550742859; E-mail: MHEGAZY@kfshrc.edu.sa

Received date: July 30, 2016; Accepted date: August 23, 2016; Published date: August 30, 2016

Copyright: (c) 2016 Hegazy MW, et al. This is an open-access article distributed under the terms of the Creative Commons Attribution License, which permits unrestricted use, distribution, and reproduction in any medium, provided the original author and source are credited.

\begin{abstract}
Background: To evaluate radiotherapy dose escalation using volumetric modulated arc therapy (VMAT) and image guided radiotherapy (IGRT) with concurrent chemotherapy in locally advanced cervix cancer (LACC) and compare it with conventional radiation therapy (CRT) in terms of the toxicity and clinical outcomes.

Methods and Materials: Data base was reviewed for all LACC patients treated either by conventional radiation therapy or dose escalation volumetric modulated arc therapy, with concurrent weekly Cisplatin $40 \mathrm{mg} / \mathrm{m}^{2}$ followed by high dose rate brachytherapy. The primary and secondary endpoints were toxicity, disease-free survival and overall survival respectively.

Results: Of 60 patients, 40 patients received CRT and 20 received VMAT. The median follow-up time in the CRT arm was 47 months (11-89), and 35 months (13-47) in the VMAT arm. Hemoglobin toxicity (Grade I-II) was encountered in $97.5 \%$ and $90 \%(p=0.03)$ while (Grade I-III) Leukopenia was $90 \%$ and $70 \%(p=0.02)$, respectively. There was no grade 3 or 4 gastrointestinal or genitourinary (GI or GU) toxicity. At 36 months, disease-free survival was $45 \%$ in the CRT group versus $75 \%$ in the VMAT group ( $p=0.03$ ), and overall survival was $65 \%$ in the CRT group versus $85 \%$ in the VMAT group $(p=0.8)$.
\end{abstract}

Conclusion: VMAT is associated with significantly less toxicity and comparable or even better clinical outcome compared with CRT. Further studies with larger sample sizes and longer follow-up times are warranted to justify its use in routine clinical practice.

Keywords: VMAT; Cervix cancer; Radiotherapy; Dose escalation treatment; Toxicity; Clinical outcome

\section{Introduction}

Cervical cancer is a major world health problem for women. The global yearly incidence of cervical cancer in 2012 was 528,000; the annual death rate was 266,000 [1]. It is the fourth most common cancer in women worldwide [2,3], with $85 \%$ of cases occurring in developing countries, where cervical cancer is a leading cause of cancer death in women $[1,4]$.

Concurrent cisplatin-based chemoradiation in combination with brachytherapy has been established as the standard treatment for locally advanced cervical carcinoma (LACC) [5]. However, the survival rates remain modest, with a 5-year disease-free survival (DFS) and overall survival (OS) of approximately $50 \%$ to $60 \%$, respectively and 5year pelvic failure rates approximating $30 \%$ with a combined modality approach [5].

Traditionally, whole pelvic radiation therapy with either a 2-field or a 4-field technique has been used, but it is associated with significant rates of gastrointestinal (GI) and hematologic toxicities $[5,6]$. Dosimetric studies have shown that intensity modulated radiation therapy (IMRT) can reduce bowel, rectal, bladder, and bone marrow dose [7-9], and early clinical studies have demonstrated lower rates of GI, genitourinary (GU), and hematologic toxicity compared with conventional techniques $[7,10,11]$.Yet, although clinical outcome has been reported to be comparable to that of conventional techniques [12-14], prospective studies comparing IMRT with conventional techniques for LACC are lacking.

In 2011, when we modified our radiation protocol, the goal was to intensify the radiation dose and volume for these typical large cancers and shorten the overall treatment time by integrating the boost (nodal and parametria/primary) within the usual 25 fractions of radiotherapy over 5 weeks. VMAT patients had a larger target volume by moving the top border (L3/L4) to systematically cover nodes around aortic bifurcation as compared to standard L4/L5 border for our historic 3DCRT patients.

We have presented our initial experience of VMAT to escalate radiation dose by simultaneous integrated boost (SIB) to gross tumor (primary and nodal) with weekly cisplatin chemotherapy and 
Citation: Hegazy MW, Mahmood R, Albadawi I, H Husaini, Moftah BA (2016) Radiotherapy Dose Escalation with Concurrent Chemotherapy Improves Outcome in Locally Advanced Cervix Carcinoma. J Nucl Med Radiat Ther 7: 304. doi:10.4172/2155-9619.1000304

Page 2 of 7

compared this with 3DCRT in terms of clinical toxicity with emphasis on hematologic toxicity and it was feasible [15]. Here we compared toxicity and survival outcomes between the 2 arms as primary and secondary objectives. This is a feasibility report for intensified radiotherapy with a longer follow-up before subjecting this approach to a randomized trial.

\section{Methods and Materials}

\section{Patient characteristics}

The medical records of women receiving concurrent chemo radiation therapy for locally advanced cervical cancer (LACC) between 2005 and 2008 were reviewed for CRT (40 patients) and database was reviewed for patients treated by VMAT/IGRT during 2011 and 2012 (20 patients). Patients who had para-aortic lymph nodes radiotherapy or required blood transfusion prior to radiotherapy were excluded.

\section{Study design}

Patients in both arms received external beam radiation therapy (EBRT) to the pelvis with concurrent administered intravenously cisplatin once a week at a dose of $40 \mathrm{mg} / \mathrm{m}^{2}$. After the completion of EBRT, all patients then received CT-based image-guided high-doserate (HDR) intra cavitary radiation therapy (ICRT), 7 Gy times three to CRT arm versus 6 Gy times four to VMAT arm. All HDR treatments were given twice a week aiming to complete both external and brachytherapy treatments within an overall time of 56 days.

\section{Radiation therapy planning}

IMRT, conventional radiation therapy and brachytherapy planning details were discussed in elsewhere [15].
Follow-up and evaluation of toxicity: After completion of treatment, patients in both arms were followed up every three month for first two years and then every six months two years after then once per year. CT scan of the abdomen and pelvis or whole body positron emission tomography/CT was obtained at the 3-month follow-up visit and then at 6-month intervals on the basis of on clinical suspicion. Patients in both arms were assessed throughout treatment and until 90 days after completion of treatment for acute toxicity then after 90 days, late toxicities were graded during follow-up according to the radiation therapy oncology group criteria (RTOG) [16].

Evaluation of outcome and statistics: The primary endpoint is the treatment toxicity and the secondary end point was disease free survival (DFS) which was measured from the initiation of concurrent chemo radiation therapy to the first event of local failure, distant metastasis, or death and overall survival (OS) was measured from the initiation of concurrent chemo radiation therapy to death of any cause. The DFS and OS were estimated by the Kaplan-Meier method [17].

A Fisher's exact test was used to compare toxicity between arms. SPSS Software, version 16.0 (SPSS Inc, Chicago, IL), was used for all data analyses, and all $\mathrm{P}$ values were based on a 2-sided hypothesis.

\section{Results}

\section{Patients}

Table 1 summarizes patient's characteristics which were discussed previously [15]; the histology distribution was squamous cell histology in $90 \%$ and $95 \%$ of CRT and VMAT respectively ( $\mathrm{p}=0.6$ ). Grade III was common (40\%) in CRT while grade II $(60 \%)$ in VMAT ( $\mathrm{p}=0.1)$.

\begin{tabular}{|l|l|l|l|}
\hline & CRT & VMAT & Mean $47(33-67)$ \\
\hline Age & Mean $46(30-63)$ & \\
\hline Stage & & $17.50 \%$ & $35 \%$ \\
\hline I & $75 \%$ & $30 \%$ & 0.002 \\
\hline II & $7.50 \%$ & $35 \%$ & $5 \mathrm{~cm}(2 \mathrm{~cm}$ to $10 \mathrm{~cm})$ \\
\hline Tumor size & $5 \mathrm{~cm}(2 \mathrm{~cm}$ to $8 \mathrm{~cm})$ & $13(65 \%)$ \\
\hline Gross pelvic nodes & $5(12.5 \%)$ & $45 \%$ & - \\
\hline Blood transfusion during therapy & $55 \%$ & 0.001 \\
\hline Pathology types & & $95 \%$ \\
\hline Squamous & $90 \%$ & $5 \%$ & 0.5 \\
\hline others & $10 \%$ & 0.6 \\
\hline Tumor grade & & $25 \%$ & $20 \%$ \\
\hline I & $35 \%$ & $60 \%$ & 0.1 \\
\hline II & $40 \%$ & $20 \%$ \\
\hline III & & \\
\hline
\end{tabular}


Citation: Hegazy MW, Mahmood R, Albadawi I, H Husaini, Moftah BA (2016) Radiotherapy Dose Escalation with Concurrent Chemotherapy Improves Outcome in Locally Advanced Cervix Carcinoma. J Nucl Med Radiat Ther 7: 304. doi:10.4172/2155-9619.1000304

Page 3 of 7

\begin{tabular}{|l|l|l|l|}
\hline Chemotherapy completed per protocol & $90 \%$ & $95 \%$ & 0.4 \\
\hline All radiotherapy completed in predefined 56 days & $78 \%$ & $90 \%$ & 0.02 \\
\hline
\end{tabular}

Table 1: Baseline and treatment parameters.

\section{Toxicity}

Treatment toxicity was recorded according to RTOG criteria and was discussed previously [15]. The difference for this hemoglobin toxicity was statistically significant in favor of VMAT with p value 0.03 . Higher incidence of leukopenia in CRT arm was statistically significant with a $p$ value of 0.02 . There was no acute G3 or G4 gastrointestinal or urogenital toxicity in both arms.

Furthermore, there was no statistical difference in number of grade 2 or below acute gastrointestinal and urogenital toxicity. With a median follow-up of 47 months (11-89) for CRT cohort and 35 months (13-47) for VMAT cohort, there is no late grade 3-4 toxicity in either arm.

\section{Outcomes and patterns of failure}

After 3 months of treatment, the complete response was $50 \%$ in CRT while 95\% in VMAT ( $\mathrm{p}=0.001$ ).After 6 and 12 months, the complete response was $50 \%$ in CRT while $90 \%$ in VMAT $(\mathrm{p}=0.003)$. After 24 months, the complete response was $47.5 \%$ in CRT while $80 \%$ in $\operatorname{VMAT}(\mathrm{p}=0.01)$.

Figures 1-8 showed the pre \& post treatment imaging with PTV50 for two patients showed complete response. At 36 months, DFS was $45 \%$ in the CRT arm versus $75 \%$ in the VMAT arm ( $\mathrm{p}=0.03)$, and OS was $65 \%$ in the CRT arm and $85 \%$ in the VMAT arm ( $\mathrm{p}=0.8)$, Figures 9 and 10.

The median progression free survival was 24 months in CRT arm but was not reached in VMAT arm. All failure cases were loco regionally and distantly in CRT arm (52.5\%) while one case (5\%) was failed loco regionally and distantly and the rest of cases (15\%) were distantly only in VMAT arm ( $\mathrm{p}=0.03)$ (Table 2).

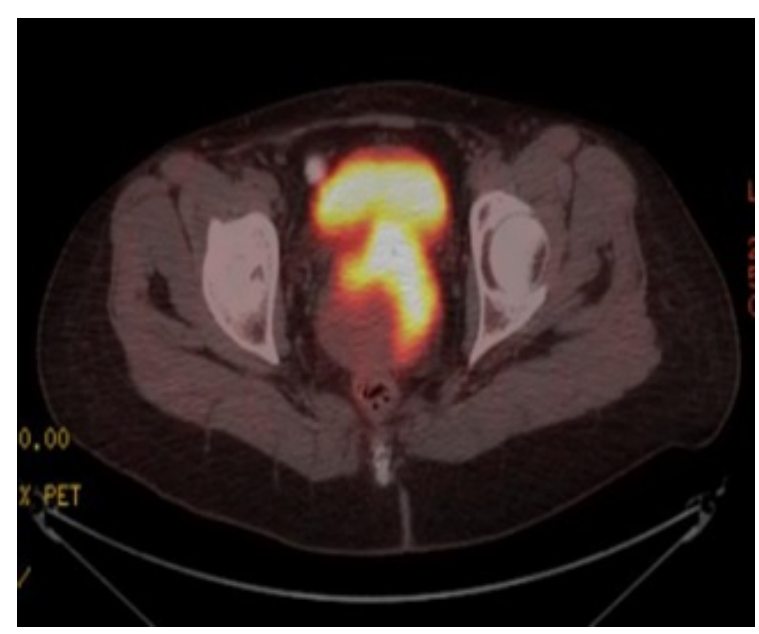

Figure 1: PET/CT pretreatment.

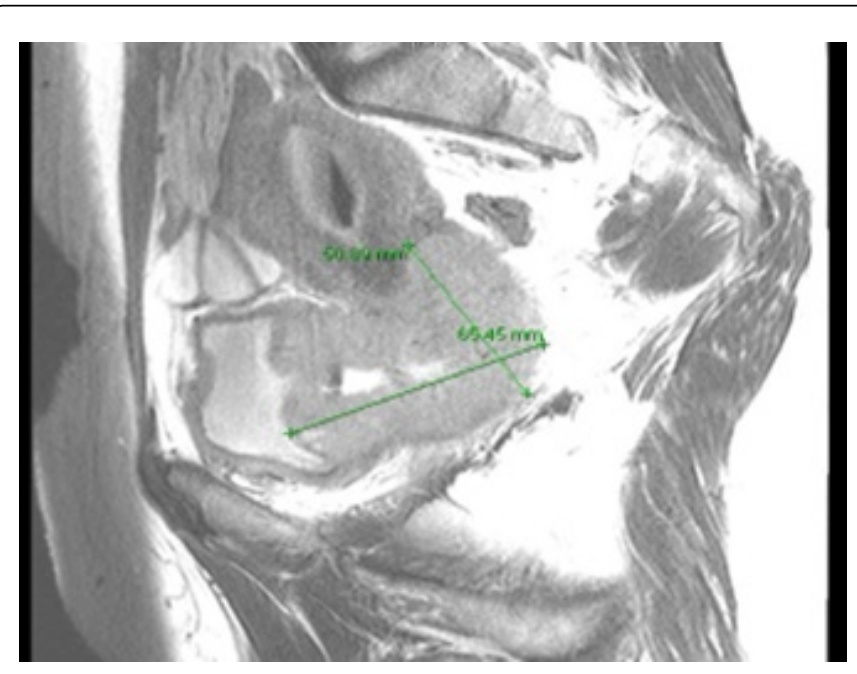

Figure 2: MRI pelvis pre treatment.
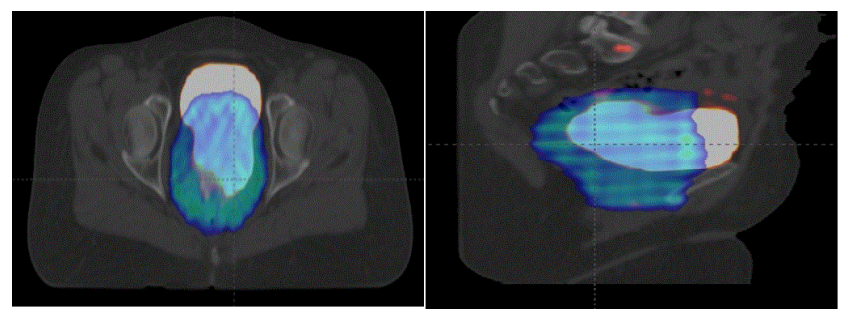

Figure 3: Dose distribution displayed on fused planning CT scan with PET/CT in color wash for PTV50.

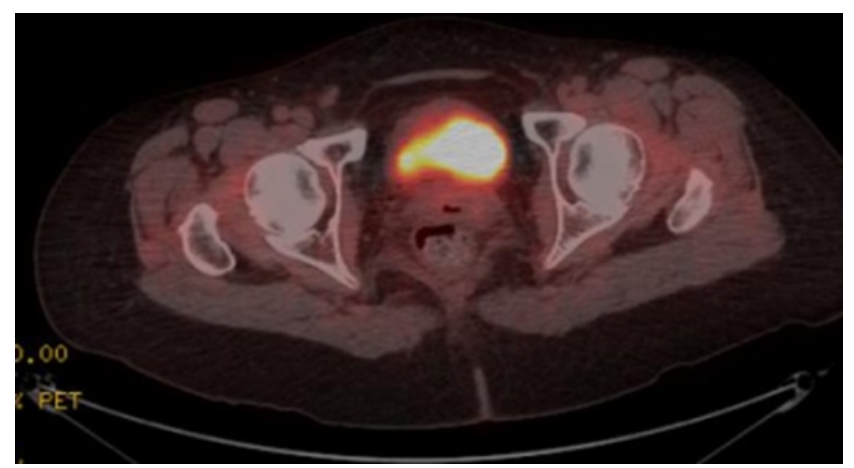

Figure 4: PET/CT 3 months post treatment with CR. 
Citation: Hegazy MW, Mahmood R, Albadawi I, H Husaini, Moftah BA (2016) Radiotherapy Dose Escalation with Concurrent Chemotherapy Improves Outcome in Locally Advanced Cervix Carcinoma. J Nucl Med Radiat Ther 7: 304. doi:10.4172/2155-9619.1000304

Page 4 of 7

\begin{tabular}{|c|c|c|c|}
\hline & CRT & VMAT & P-value \\
\hline \multicolumn{4}{|c|}{ Hemoglobin toxicity } \\
\hline Grade I-II & $97.50 \%$ & $90 \%$ & \multirow[t]{4}{*}{0.03} \\
\hline $\mathrm{BMH}(\mathrm{g} / \mathrm{l})$ & 121.4 & 115 & \\
\hline AWH $(\mathrm{g} / \mathrm{l})$ & 115.7 & 109 & \\
\hline $\mathrm{MDH}(\mathrm{g} / \mathrm{l})$ & 20 & 17 & \\
\hline \multicolumn{4}{|l|}{ WBCs toxicity } \\
\hline Grade I-III & $90 \%$ & $70 \%$ & \multirow[t]{4}{*}{0.02} \\
\hline BMW $(\times 109 / l)$ & 7 & 7 & \\
\hline AWW (×109/l) & 4 & 5 & \\
\hline MDW (×109/I) & 4.7 & 5.4 & \\
\hline \multicolumn{4}{|l|}{ GI toxicity } \\
\hline Grade I-II & $67.50 \%$ & $40 \%$ & 0.1 \\
\hline \multicolumn{4}{|l|}{ GU toxicity } \\
\hline Grade I-II & $35 \%$ & $20 \%$ & 0.2 \\
\hline \multicolumn{4}{|c|}{ Complete Response } \\
\hline 3 months & $50 \%$ & $95 \%$ & 0.001 \\
\hline 6 months & $50 \%$ & $90 \%$ & 0.003 \\
\hline 12 months & $50 \%$ & $90 \%$ & 0.003 \\
\hline 24 months & $47.50 \%$ & $80 \%$ & 0.01 \\
\hline
\end{tabular}

Table 2: Radiation toxicity and response.

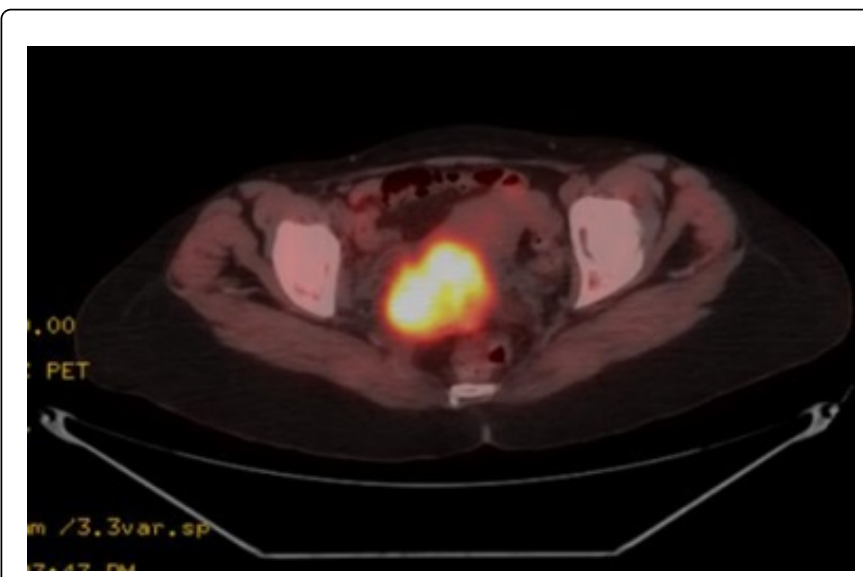

Figure 5: PET/CT pretreatment.

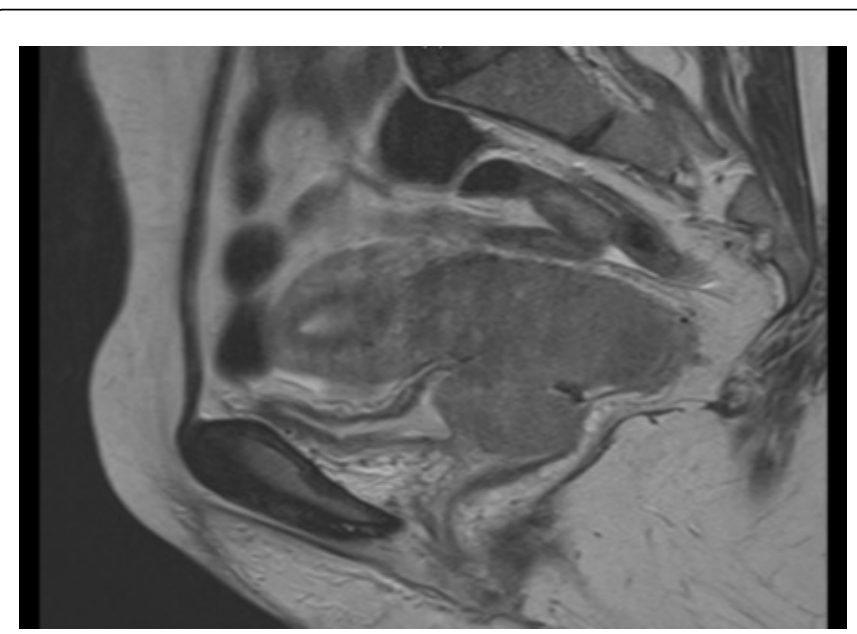

Figure 6: MRI pelvis pre-treatment. 
Citation: Hegazy MW, Mahmood R, Albadawi I, H Husaini, Moftah BA (2016) Radiotherapy Dose Escalation with Concurrent Chemotherapy Improves Outcome in Locally Advanced Cervix Carcinoma. J Nucl Med Radiat Ther 7: 304. doi:10.4172/2155-9619.1000304

Page 5 of 7

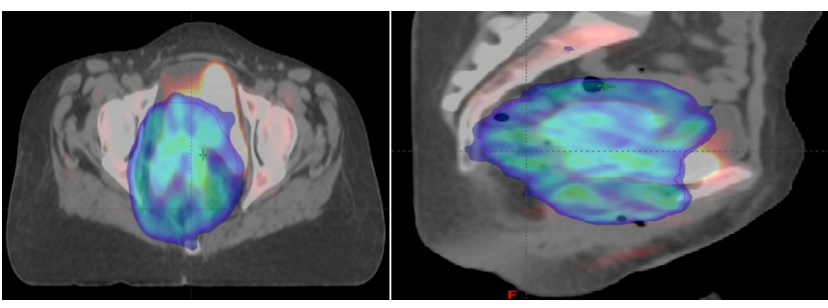

Figure 7: Dose distribution displayed on fused planning CT scan with PET/CT in color wash for PTV50.

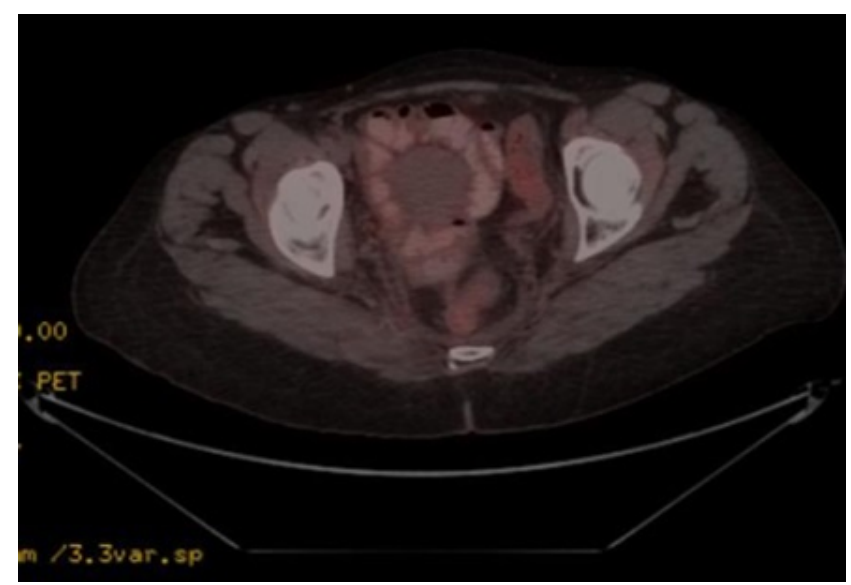

Figure 8: PET/CT 3 months post treatment with CR.

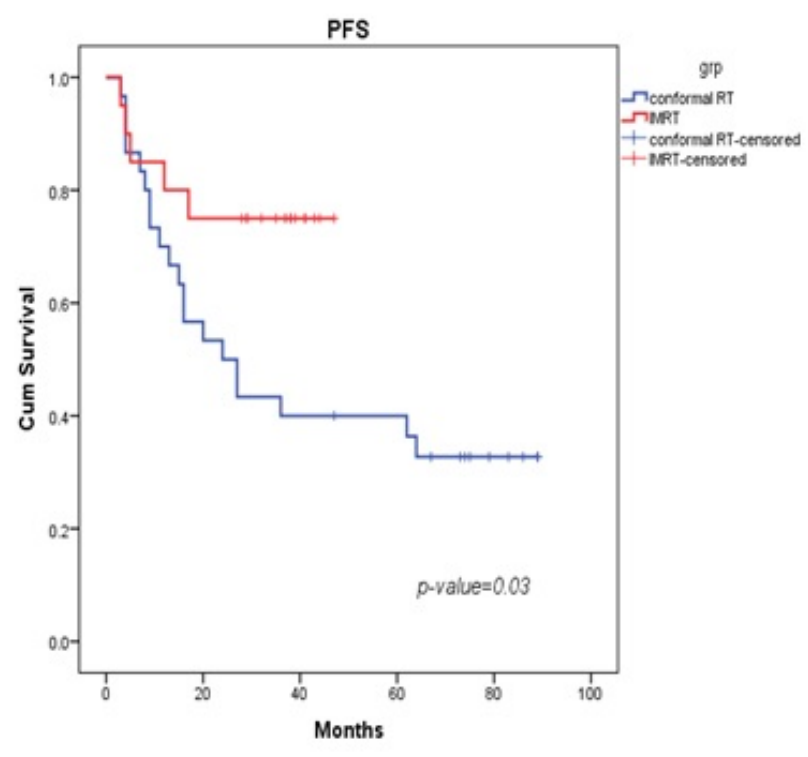

Figure 9: Progression free survival curve.

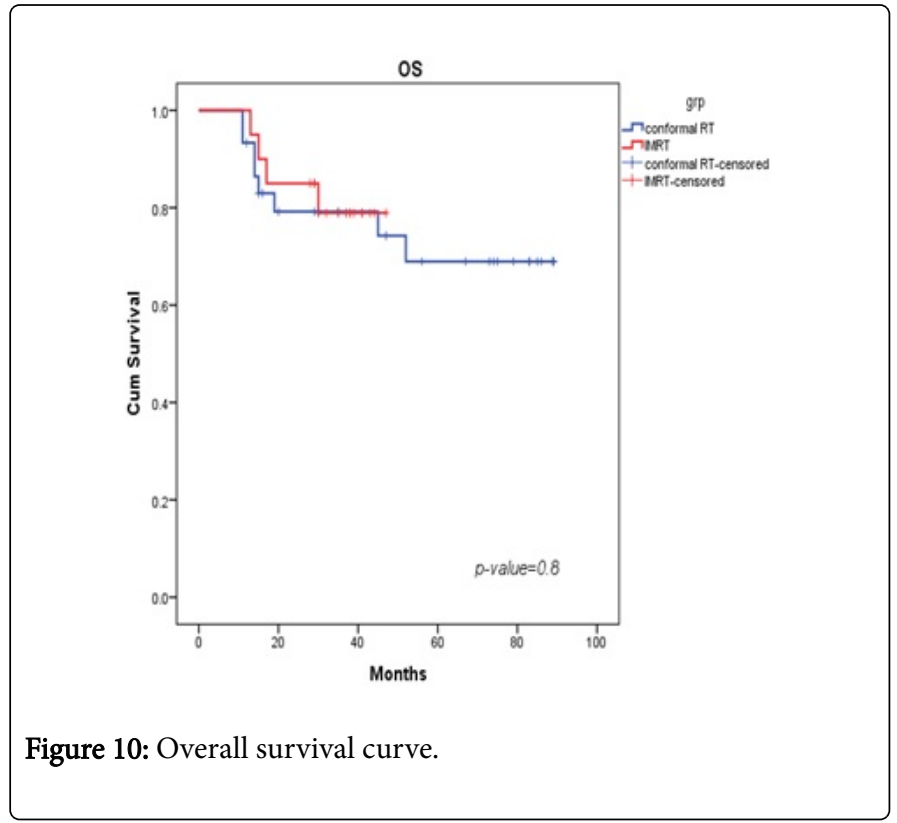

\section{Discussion}

Conventional radiation therapy remains the gold standard for LACC. Preliminary studies have shown reduced toxicities and comparable clinical outcomes with IMRT compared with CRT, and despite a lack of prospective randomized data to support its use, the use of IMRT for gynecologic malignancies, including LACC, has increased over the last decade [18].

Our study aimed to evaluate the toxicity and clinical outcomes of radiotherapy dose escalation to gross tumor by simultaneous integrating boost within conventional 25 fractions (SIB) using volumetric modulated arc therapy (VMAT) in locally advanced cervix cancer (LACC).

Our study has shown that despite larger volume treated (superior border at L3/L4 for VMAT and L4/L5 for 3DCRT group) to a higher radiation dose, toxicity and clinical outcomes were significantly better with bone marrow-sparing VMAT approach. It is also to be noted that there were more patients with advanced Stage III cancers with higher proportion of pelvic nodes in VMAT arm. Advances in imaging, in particular with FDG-PET and MRI, have also brought about changes in the treatment of cervical cancer by helping to better define areas of disease.

The results of previous retrospective studies 12-14 support our findings. Rose et al. [19] reported 3-year OS of $51.4 \%$ to $61.4 \%$ for 47 cervical cancer patients treated with IMRT for stage IIB-IIIB disease. Du et al. [14] reported a significant improvement in 5-year progression-free survival rates with IMRT but no improvement in OS in a retrospective comparison of IMRT and conventional radiation therapy.

Gandhi et al. [20] reported a DFS (60\% in IMRT vs $79.4 \%$ in CRT) and OS $(85.7 \%$ in IMRT vs $76 \%$ in CRT) were not statistically different between arms at 27 months, but in as much as the median time to recurrence may be as long as 36 months, longer follow-up times may be useful in clarifying this discrepancy. 
Citation: Hegazy MW, Mahmood R, Albadawi I, H Husaini, Moftah BA (2016) Radiotherapy Dose Escalation with Concurrent Chemotherapy Improves Outcome in Locally Advanced Cervix Carcinoma. J Nucl Med Radiat Ther 7: 304. doi:10.4172/2155-9619.1000304

Page 6 of 7

In our study, DFS (75\% in VMAT vs $45 \%$ in CRT) was statistically different between arms at 36 months $(\mathrm{p}=0.03)$ while OS $(85 \%$ in VMAT vs $65 \%$ in CRT) was not $(\mathrm{p}=0.8)$, but longer follow-up times may clarify this discrepancy. Table 4 provides a review of prior studies for the purpose of comparison, the 3 earlier studies, like the study reported here, and there is only one randomized prospective trial [20].

\begin{tabular}{|c|c|c|c|c|c|c|c|c|}
\hline \multirow{3}{*}{ Reference } & \multirow{3}{*}{$\begin{array}{l}\text { No. (No. of } \\
\text { IMRT } \\
\text { patients) }\end{array}$} & \multirow{3}{*}{ Study type } & $\begin{array}{l}\text { Median } \\
\text { follow up }\end{array}$ & Grade $\geq 2$ & \multirow{2}{*}{$\begin{array}{l}\text { Grade } \geq 3 \\
\text { GI toxicity }\end{array}$} & \multirow{2}{*}{$\begin{array}{l}\text { Grade } \geq 2 \\
\text { GU toxicity }\end{array}$} & \multirow{2}{*}{$\begin{array}{l}\text { Grade } \geq 3 \\
\text { GU toxicity }\end{array}$} & \multirow{3}{*}{$\begin{array}{l}\begin{array}{l}\text { Clinical } \\
\text { outcome }\end{array} \\
\text { (IMRT vs CRT) }\end{array}$} \\
\hline & & & $\begin{array}{l}\text { (IMRT vs. } \\
\text { CRT) }\end{array}$ & GI toxicity & & & & \\
\hline & & & & $\begin{array}{l}\text { (IMRT vs. } \\
\text { CRT) }\end{array}$ & $\begin{array}{l}\text { (IMRT vs. } \\
\text { CRT) }\end{array}$ & $\begin{array}{l}\text { (IMRT vs. } \\
\text { CRT) }\end{array}$ & $\begin{array}{l}\text { (IMRT vs. } \\
\text { CRT) }\end{array}$ & \\
\hline Du et al. [14] & $122(60)$ & Retrospective & $47(6-68)$ & $\begin{array}{ll}17.6 \% & \text { vs. } \\
31.60 \% & \\
(p=0.03) Z & \end{array}$ & $\begin{array}{l}5.3 \text { vs. } 8.30 \% \\
(p=0.03) Z\end{array}$ & $\begin{array}{l}14.1 \quad \text { vs. } \\
38.30 \% \\
(p=0.001) Z\end{array}$ & $\begin{array}{ll}7.1 \% & \text { vs. } \\
18.30 \% & \\
(p=0.001) Z & \end{array}$ & $\begin{array}{l}5 \text { year PFS } \\
64.9 \% \text { vs. } 44.3 \% \\
(p=0.03) \\
3 \text { year OS } 90.7 \\
\text { vs. } 91.3 \%(N S)\end{array}$ \\
\hline Kidd et al. [13] & 452 (135) & Retrospective & $52(5-117)$ & NA & $\begin{array}{l}5.18 \% \text { ys. } \\
10.72 \% \text { y, }\end{array}$ & NA & $\begin{array}{l}0.74 \% \text { vs. } 6.3 \% \\
y, z\end{array}$ & $\begin{array}{l}\text { No difference in } \\
\text { RFS; OS better } \\
\text { in IMRT arm } \\
(\mathrm{p}<0.0001)\end{array}$ \\
\hline $\begin{array}{l}\text { Thawani et al. } \\
\text { [21] }\end{array}$ & 96 (39) & Retrospective & NA & NA & $\begin{array}{l}4 \% \text { vs. } 21 \% \\
(P<0.01)\end{array}$ & NA & $\begin{array}{l}2 \% \\
(p<0.01)\end{array}$ & NA \\
\hline $\begin{array}{l}\text { Gandhi et al. } \\
\text { [20] }\end{array}$ & $44(22)$ & $\begin{array}{l}\text { Prospective } \\
\text { randomized }\end{array}$ & $\begin{array}{l}21.6 \\
(7.7-34.4) \text { vs. } \\
21.7 \\
(10.7-37.4)\end{array}$ & $\begin{array}{l}31.8 \% \quad \text { vs. } \\
63.60 \% \\
(p=0.034) x\end{array}$ & $\begin{array}{l}4.5 \% \quad \text { vs. } \\
27.30 \% \\
(p=0.047) x\end{array}$ & $\begin{array}{ll}23.8 \% & \text { vs. } \\
31.80 \% & \\
(p=0.40) \times & \end{array}$ & $\begin{array}{l}0 \% \text { vs. } 13.6 \% \\
(p=0.125) \times\end{array}$ & $\begin{array}{l}\text { At } 27 \text { months, } \\
\text { DFS } 60 \% \text { vs. } \\
79.4 \% \quad(p 0.651) \\
\text { OS } 85.7 \% \\
\text { vs. } 76 \%(p 0.645)\end{array}$ \\
\hline Present series & $60(20)$ & Retrospective & $\begin{array}{l}35(13-47) \\
\text { vs. } \\
47(11-89)\end{array}$ & $\begin{array}{l}40 \% \\
67.50 \% \\
(p=0.1)\end{array}$ & NA & $\begin{array}{l}20 \% \text { vs. } 35 \% \\
(p=0.2)\end{array}$ & NA & $\begin{array}{l}\text { At } 36 \text { months, } \\
\text { DFS was } 45 \% \text { vs } \\
75 \% \text { (p .03), OAS } \\
65 \% \text { vs } 85 \% \text { (p } \\
0.8 \text { ) }\end{array}$ \\
\hline
\end{tabular}

Abbreviations: $\mathrm{CRT}=$ conventional radiation therapy; DFS = disease-free survival; $\mathrm{GI}=$ gastrointestinal; GU = genitourinary; IMRT = intensity modulated radiation therapy; NA = not applicable; NS = not significant; OS = overall survival; PFS = progression-free survival; RFS = recurrence free survival. * Midline blocks were used in the conventional radiation therapy arm and reduced field IMRT was used. $Y=$ Chronic toxicity per Radiation Therapy Oncology Group criteria. $Z=$ Toxicity graded per Radiation Therapy Oncology Group criteria.

$\mathrm{X}=$ Toxicity graded per Common Terminology Criteria for Adverse Events, version 3.0.

Table 4: Clinical outcomes and toxicity of selected studies comparing IMRT versus conventional radiation therapy in locally advanced cervical carcinoma.

Notably, although the overall survival outcomes are not statistically different between arms, we did observe a significant benefit in regard to toxicity and progression free survival. Another advantage of our study is the use of image guidance. The main limitation of our study is a relatively modest sample size and limited times of follow-up. The lower rates of hematologic toxicity with VMAT in our study could be related to the use of bone marrow-sparing techniques, as has been suggested by recent studies [19]. Although the issue has been debatable until now, we seem to be progressing toward a standardized approach to IMRT for intact cervical cancer patients. The results of our study should lend support for the pursuit of further studies and open avenues for prospective multi institutional studies to further define the role of IMRT in LACC.

\section{Conclusion}

In our experience of 60 women with LACC treated with chemoradiation therapy, VMAT resulted in a lower rate of hematological toxicity and comparable clinical outcome than CRT. Further studies with larger sample sizes and longer follow-up times are needed to define the role of VMAT in the management of LACC.

\section{Compliance with ethical standards}

This study has been approved by the institutional ethics committee and has been performed in accordance with the ethical standards laid down in the 1964 Declaration of Helsinki. All persons gave their informed consent prior to therapy; however, for retrospective review of data with less than minimal risk to the patients, no consent was 
Citation: Hegazy MW, Mahmood R, Albadawi I, H Husaini, Moftah BA (2016) Radiotherapy Dose Escalation with Concurrent Chemotherapy Improves Outcome in Locally Advanced Cervix Carcinoma. J Nucl Med Radiat Ther 7: 304. doi:10.4172/2155-9619.1000304

Page 7 of 7

required by the ethics committee. All authors declare that there is no conflict of interest.

\section{References}

1. International Agency for Research on Cancer (2012) Cervical Cancer Estimated Incidence, Mortality and Prevalence Worldwide in 2012. World Health Organization, Geneva, Switzerland.

2. Parkin DM, Bray F, Ferlay J, Pisani P (2005) Global cancer statistics 2002. CA Cancer J Clin 55: 74-7108.

3. Kamangar F, Dores GM, Anderson WF (2006) Patterns of cancer incidence, mortality and prevalence across five continents: defining priorities to reduce cancer disparities in different geographic regions of the world. J Clin Oncol 24: 2137-2150.

4. Jemal A, Bray F, Center MM, Ferlay J, Ward E, et al. (2011) Global cancer statistics. CA Cancer J Clin 61: 69-90.

5. Perez CA, Kavanagh BD (2008) Uterine cervix. In: Halperin EC, Perez CA, Brady LW, Perez and Brady's Principles and Practices of Radiation Oncology. (5th edn.), Philadelphia: Lippincott Williams \& Wilkins, pp: 1593-1595.

6. John M, Flam M, Caplan R, Rotman M, Quivey J, et al. (1996) Final results of a phase II chemoradiation protocol for locally advanced cervical cancer: RTOG 85e15. Gynecol Oncol 61: 221-226.

7. Lujan AE, Mundt AJ, Yamada SD, Rotmensch J, Roeske C (2003) Intensity-modulated radiotherapy as a means of reducing dose to bone marrow in gynecologic patients receiving whole pelvic radiotherapy. Int J Radiat Oncol Biol Phys 57: 516-521.

8. Mell LK, Tiryaki H, Ahn KH, Mundt AJ, Roeske JC, et al. (2008) Dosimetric comparison of bone marrow-sparing intensity-modulated radiotherapy versus conventional techniques for treatment of cervical cancer. Int J Radiat Oncol Biol Phys 71: 1504-1510.

9. Roeske JC, Bonta D, Mell LK, Lujan AE, Mundt AJ, et al. (2003) A dosimetric analysis of acute gastrointestinal toxicity in women receiving intensity modulated whole-pelvic radiation therapy. Radiother Oncol 69: 201-207.

10. Brixey CJ, Roeske JC, Lujan AE, Yamada SD, Rotmensch J, et al. (2002) Impact of intensity modulated radiotherapy on acute hematologic toxicity in women with gynecologic malignancies. Int J Radiat Oncol Biol Phys 54: 1388-1396.
11. Mundt AJ, Mell LK, Roeske JC, Salma JK (2003) Preliminary analysis of chronic gastrointestinal toxicity in gynecology patients treated with intensity modulated whole pelvic radiation therapy. Int J Radiat Oncol Biol Phys 56: 1354-1360.

12. Kidd EA, Siegel BA, Dehdashti F, Rader JS, Mutic S, et al. (2011) Clinical outcome of Intensity modulated radiation therapy for carcinoma of cervix. Int J Radiat Oncol Biol Phys 80: 1436-1445.

13. Kidd EA, Siegel BA, Dehdashti F, Rader JS, Mutic S, et al. Clinical outcomes of definitive intensity modulated radiation therapy with flurodeoxy glucose positron emission tomography simulation in patients with locally advanced cervical cancers. Int J Radiat Oncol Biol Phys 77: 1085-1091.

14. Du XL, Tao J, Sheng XG, Lu CH, Yu H, et al. (2012) Intensity-modulated radiation therapy for advanced cervical cancer: A comparison of dosimetric and clinical outcomes with conventional radiotherapy. Gynecol Oncol 125: 152-157.

15. Hegazy MW, Mahmood RI, Al-Badawi IA (2016) Radiotherapy dose escalation with concurrent chemotherapy in locally advanced cervix cancer is feasible. Clin Transl Oncol 18: 58-64.

16. Cox JD, Stetz J, Pajak TF (1995) Toxicity criteria of the Radiation Therapy Oncology Group (RTOG) and the European Organization for Research and Treatment of Cancer (EORTC). Int J Radiat Oncol Biol Phys 31: 1341-1346.

17. Kaplan EL, Meier P (1958) Nonparametric estimation from incomplete observations. J Am Stat Assoc 53: 457-481.

18. Mell LK, Mehrotra AK, Mundt AJ (2005) Intensity-modulated radiation therapy use in the U.S., 2004. Cancer 104: 1296-1303.

19. Rose BS, Aydogan B, Liang Y, Yeginer M, Hasselle MD, et al. (2011) Normal tissue complication probability modeling of acute hematologic toxicity in cervical cancer patients treated with chemoradiotherapy. Int J Radiat Oncol Biol Phys 79: 800-807.

20. Gandhi AK, Daya NS, Goura KR, Julka PK, Subramani V, et al. (2013) Early Clinical Outcomes and Toxicity of Intensity Modulated Versus Conventional Pelvic Radiation Therapy for Locally Advanced Cervix Carcinoma: A Prospective Randomized Study; Int J Radiation Oncol Biol Phys 87: 542-548.

21. Thawani N, Vainshtein JM, Hannan R (2008) Comparison of intensity modulated radiation therapy (IMRT) with conventional radiotherapy for cervical cancer with concurrent cisplatin. J Clin Oncol 26: 5562. 